Research Article

\title{
Electrical Characterization of Si/ZnO Nanorod PN Heterojunction Diode
}

\author{
Sadia Muniza Faraz $\left(\mathbb{D},{ }^{1}\right.$ Wakeel Shah, ${ }^{1}$ Naveed Ul Hassan Alvi, ${ }^{2}$ Omer Nur ${ }^{10},{ }^{3}$ \\ and Qamar Ul Wahab ${ }^{4}$ \\ ${ }^{1}$ Electronic Design Center, Department of Electronic Engineering, NED University of Engineering and Technology, \\ Karachi-75270, Pakistan \\ ${ }^{2}$ Laboratory of Organic Electronics, Department of Science and Technology, Linköping University, Linköping S-60174, Sweden \\ ${ }^{3}$ Department of Science and Technology (ITN), Faculty of Science \& Engineering, Linkoping University, Linköping, Sweden \\ ${ }^{4}$ University of Technology, Nowshera-24100, Pakistan \\ Correspondence should be addressed to Sadia Muniza Faraz; smuniza@neduet.edu.pk
}

Received 22 July 2019; Accepted 16 March 2020; Published 13 April 2020

Academic Editor: Yuri Galperin

Copyright (C) 2020 Sadia Muniza Faraz et al. This is an open access article distributed under the Creative Commons Attribution License, which permits unrestricted use, distribution, and reproduction in any medium, provided the original work is properly cited.

\begin{abstract}
The electrical characterization of p-Silicon ( $\mathrm{Si}$ ) and n-Zinc oxide $(\mathrm{ZnO})$ nanorod heterojunction diode has been performed. $\mathrm{ZnO}$ nanorods were grown on p-Silicon substrate by the aqueous chemical growth (ACG) method. The SEM image revealed high density, vertically aligned hexagonal $\mathrm{ZnO}$ nanorods with an average height of about $1.2 \mu \mathrm{m}$. Electrical characterization of $\mathrm{n}-\mathrm{ZnO}$ nanorods/p-Si heterojunction diode was done by current-voltage (I-V), capacitance-voltage (C-V), and conductance-voltage (GV) measurements at room temperature. The heterojunction exhibited good electrical characteristics with diode-like rectifying behaviour with an ideality factor of 2.7, rectification factor of 52, and barrier height of $0.7 \mathrm{~V}$. Energy band (EB) structure has been studied to investigate the factors responsible for small rectification factor. In order to investigate nonidealities, series resistance and distribution of interface state density $\left(\mathrm{N}_{\mathrm{SS}}\right)$ below the conduction band $(\mathrm{CB})$ were extracted with the help of I-V and C-V and G-V measurements. The series resistances were found to be $0.70,0.73$, and $0.75 \mathrm{~K} \Omega$, and density distribution interface states from $8.38 \times 10^{12}$ to $5.83 \times 10^{11} \mathrm{eV}^{-1} \mathrm{~cm}^{-2}$ were obtained from $0.01 \mathrm{eV}$ to $0.55 \mathrm{eV}$ below the conduction band.
\end{abstract}

\section{Introduction}

Zinc oxide $(\mathrm{ZnO})$ is a promising and environment friendly semiconductor with a large exciton binding energy $(60 \mathrm{meV})$ and a direct and wideband gap $(3.37 \mathrm{eV})$. It has superior physical properties such as high breakdown electric field, high electron saturation velocity; radiation tolerance, and thermal conductivity [1], which enable it for making high-power and high-temperature devices. Being a transparent conducting oxide, it has a potential to replace indium tin oxide (ITO) in photovoltaics. Short-wavelength light emitters and detectors working at nearultraviolet (UV) wavelengths can be made from $\mathrm{ZnO}$.

Electronic-grade bulk, thin film, and nanostructured $\mathrm{ZnO}$ can be grown easily and cheaply on a variety of substrates by different growth or deposition methods along with the tailoring of band gap [2-5]. Homojunctions of $\mathrm{ZnO}$ are difficult to realize because reproducible p-type with desired hole concentration without diminution is still under research $[6,7]$. However, heterojunctions of $\mathrm{ZnO}$ are realized with various semiconductors most commonly Si, GaN, and $\mathrm{SiC}$ for the fabrication of LEDs, Photodetectors, solar cells, biosensors, etc. [8-11].

For the realization of $\mathrm{ZnO}$ heterojunction, silicon is the most attractive choice because of its low cost and large area wafers. Therefore, fabrication of $\mathrm{Si} / \mathrm{ZnO}$ heterojunction by different techniques has been a topic of interest, and several studies have been reported on their characterizations and device fabrication for potential applications [12-15].

In the present work, we are reporting the growth, fabrication, and characterization results of $\mathrm{p}-\mathrm{Si} / \mathrm{n}-\mathrm{ZnO}$ nanorod 
heterojunction diodes. The structural, optical, and electrical characteristics are studied by scanning electron microscopy (SEM), photoluminescence (PL), current-voltage (I-V), and capacitance-voltage $(\mathrm{C}-\mathrm{V})$ measurements. Electrical parameters including barrier height $\left(\varphi_{\mathrm{B}}\right)$, ideality factor $(n)$, series resistance $(R \mathrm{~s})$, doping density $\left(\mathrm{N}_{\mathrm{d}}\right)$, and interface states density $\left(\mathrm{N}_{\mathrm{SS}}\right)$ are also reported.

\section{Materials and Methods}

$\mathrm{ZnO}$ nanorods have been grown on $\mathrm{p}$-Si substrates of (100) orientation with doping of $10^{16} \mathrm{~cm}^{-3}$ and $1.38 \Omega \mathrm{cm}$ conductivity. Prior to growth, the substrates were ultrasonically cleaned for 15 minutes with each acetone and methanol and then rinsed with deionized water sequentially to remove contamination and dust from the surface.

$\mathrm{ZnO}$ nanorods were grown by the renowned lowtemperature aqueous chemical growth (ACG) method [16-19]. Initially, a seed layer solution was prepared by diluting zinc acetate dehydrate in methanol. Few droplets of seed solution were spin-coated on the substrates. The coating step was repeated three times, and then samples were heated at $250^{\circ} \mathrm{C}$ in air for $20 \mathrm{~min}$ to yield layers of $\mathrm{ZnO}$ on the substrate. For the preparation of solution, analytic reagent grade hexamethylenetetramine (HMT) $\left(\mathrm{C}_{6} \mathrm{H}_{12} \mathrm{~N}_{4}\right)$ and zinc nitrate $\left(\mathrm{Zn}\left(\mathrm{NO}_{3}\right) 26 \mathrm{H}_{2} \mathrm{O}\right) \quad 0.022-0.075 \mathrm{mM}$ were used without further purification. The solution was prepared with an equimolar concentration of zinc nitrate and hexamethylenetetramine by dissolving in $200 \mathrm{ml}$ of deionized water at room temperature. In order to get a homogeneous solution it was stirred at $60^{\circ} \mathrm{C}$ for 30 minutes by magnetic stirring for complete mixing. The samples were then placed in solution with seed layer faced down with a certain angle. The container of solution was sealed with an aluminium foil and heated at $96^{\circ} \mathrm{C}$ for 4 hours. After growth process, the samples were washed with deionized water for removing organic salts and blow-dried with nitrogen.

For the fabrication of heterojunction, an insulating layer of polymethyl methacrylate (PMMA) was spin-coated on the samples to fill the gaps between the nanorods. PMMA layer prevents the carrier cross-talk among the nanorods. It also isolates the electrical contacts, deposited at the top of nanorods, from reaching the Si substrate. Then, oxygen plasma cleaning was performed to remove excess PPMA from the top of the nanorods. About $150 \mathrm{~nm}$ thick ohmic contact of aluminium ( $\mathrm{Al}$ ) has been evaporated in the vacuum chamber on $\mathrm{p}-\mathrm{Si}$ substrate. $\mathrm{Al} / \mathrm{Pt}$ nonalloyed circular contacts were then evaporated to form ohmic contacts to $\mathrm{n}-\mathrm{ZnO}$ nanorods. The thickness of $\mathrm{Pt} / \mathrm{Al}$ contacts was $50 / 60 \mathrm{~nm}$ with a diameter of $0.58 \mathrm{~mm}$ and specific contact resistance of $1.2 \times 10^{-5} \Omega-\mathrm{cm}^{-2}$. $\mathrm{ZnO}$ nanorods' growth and device fabrication steps are shown in Figure 1.

The structural characteristics of $\mathrm{ZnO}$ nanorods were studied by using the JEOLJSM-6301F scanning electron microscope (SEM). Current-voltage (I-V) and capacitancevoltage $(\mathrm{C}-\mathrm{V})$ measurements have been performed by using Keithley SCS -4200 by placing the sample on a probe station.
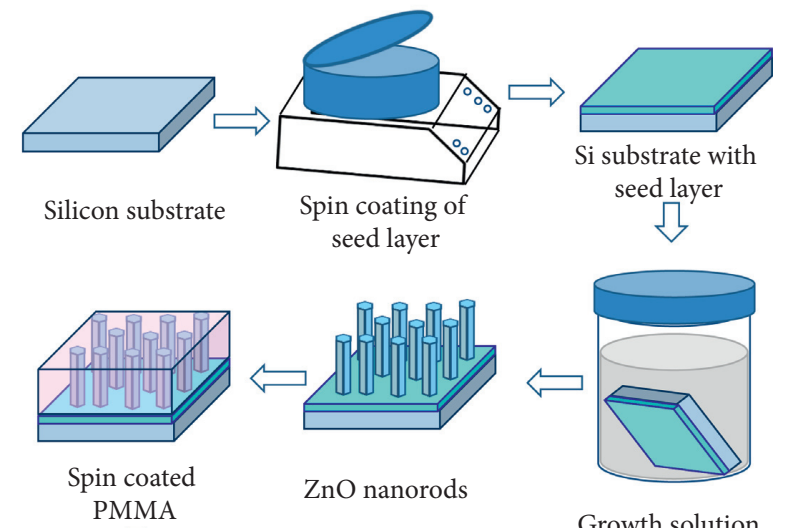

り

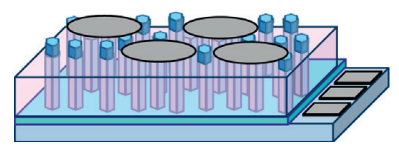

Schematic $\mathrm{ZnO} / \mathrm{Si}$ heterojunction after etching and metallization

Growth solution

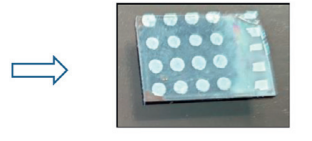

$\mathrm{ZnO} / \mathrm{Si}$

heterojunction

FIgURE 1: Step-by-step growth and device fabrication procedures.

\section{Results and Discussion}

The morphology and size distribution of $\mathrm{ZnO}$ nanorods were studied by SEM. Vertically aligned, dense array of hexagon-shaped nanorods with a mean diameter of $180-300 \mathrm{~nm}$ and approximate height of $1.4 \mu \mathrm{m}$ are revealed as shown in Figure 2. Although the nanorods were not perfectly aligned on the substrate, they had a tendency to grow vertical on the substrate with an almost uniform distribution. The standard aspect ratio (SAR) of 4.66-7.77 has been obtained by dividing the length of rods with its diameter which is in agreement with reported values for hydrothermally grown $\mathrm{ZnO}$ nanorods [20, 21].

Current-voltage (I-V) characteristics of the $\mathrm{Si} / \mathrm{ZnO}$ pn heterojunction have been studied at room temperature for a voltage range from -10 to $+10 \mathrm{~V}$ as shown in Figure 3; inset shows the schematic of $\mathrm{Si} / \mathrm{ZnO}$ heterojunction.

These characteristics show a nonlinear rectifying behaviour with turn-on voltage of $0.6 \mathrm{~V}$. The current rectification factor $\left(I_{\text {Forward }} / I_{\text {Reverse }}\right)$ was found to be 52 measured at $\pm 5 \mathrm{~V}$. The values of ideality factor $(n)$ and barrier height $\left(\phi_{\mathrm{B}}\right)$ are extracted by using the Shockley equation based on the thermionic emission model given by equations (1) and (2).

$$
\begin{gathered}
n=\frac{q V}{k T}\left\{\frac{1}{\ln \left(\left(I / I_{o}\right)+1\right)}\right\}, \\
\phi_{B}=-\frac{k_{B} T}{q} \ln \left(\frac{I_{o}}{A A^{*} T^{2}}\right),
\end{gathered}
$$

where $A$ is the area $\left(10.86 \times 10^{-3} \mathrm{~cm}^{2}\right), I_{\mathrm{o}}$ is the saturation current, $k_{\mathrm{B}}$ is Boltzmann's constant, and $A^{*}$ is the Richardson constant having a value of $32 \mathrm{~A} / \mathrm{cm}^{2} \mathrm{~K}^{2}$ for $\mathrm{n}-\mathrm{ZnO}$. The Richardson constant is extracted from $A^{*}=120 \times \mathrm{m}^{*} / \mathrm{m}_{\mathrm{o}} \mathrm{A} / \mathrm{cm}^{2} \mathrm{~K}^{2}$, where $\mathrm{m}^{*}$ is the effective mass for $\mathrm{ZnO}$ taken as $0.275 \mathrm{~m}_{\mathrm{o}}$ for electrons [17]. 


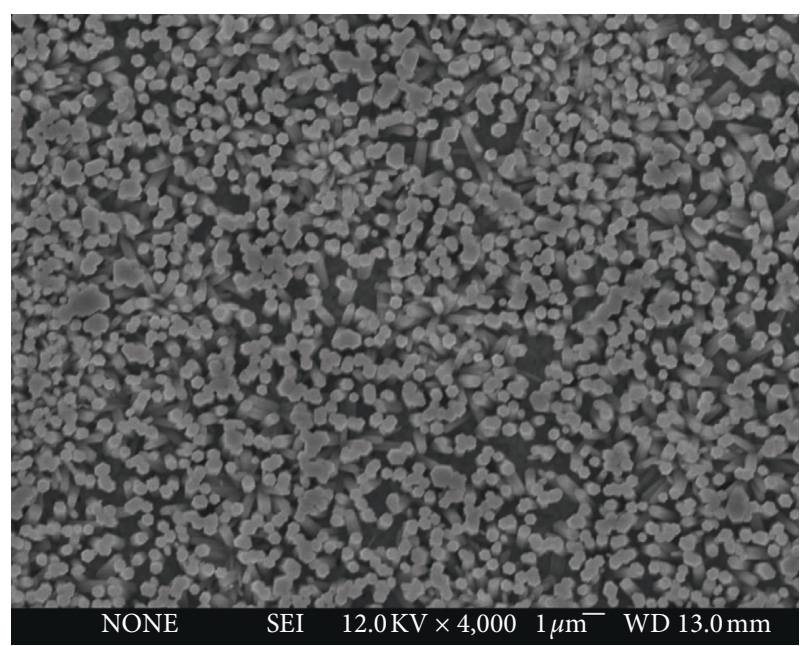

FIGURE 2: SEM image of $\mathrm{ZnO}$ nanorods grown on $\mathrm{p}$-Si substrate.

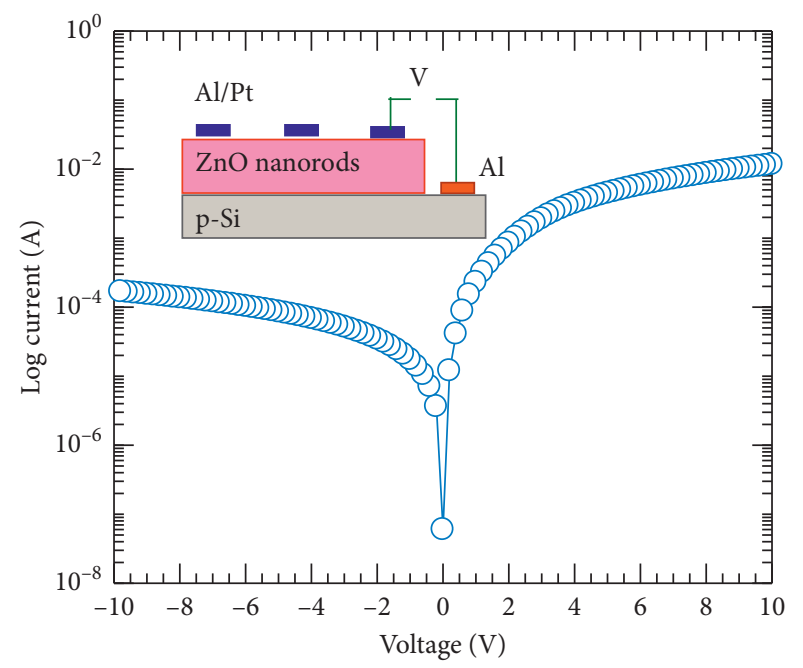

FIGURE 3: Current voltage characteristics of $\mathrm{Si} / \mathrm{ZnO}$ heterojunction.

The values of ideality factor and barrier height obtained are 2.7 and $0.70 \mathrm{~V}$, respectively. A high value of ideality factor is attributed to series resistance and presence of interface sates.

To study the charge transport mechanism of $\mathrm{Si} / \mathrm{ZnO}$ heterojunction, the logarithmic plot of current-voltage (Log $I$-Log $V$ ) under forward bias has been studied.

For our heterojunction, the $\log I-\log V$ plot is having three regions as shown in Figure 4. Region-I is low forward voltage $(V<0.6 \mathrm{~V})$ with a linear $(I \sim V)$ current-voltage relationship representing an ohmic current transport mechanism. This implies that tunnelling may be responsible for charge transport. The small value of current is due to limited carrier injection from the electrodes into the semiconductor under low biases.

Region-II is for moderate forward voltages $(0.8 \mathrm{~V}<\mathrm{V}<3.4 \mathrm{~V})$. For this region, an exponential increment in current is observed with an increase in the voltage following the relation $I \sim e^{\mathrm{KV}}$, where $\mathrm{K}$ is a constant known as injection efficiency constant. The higher values of $K$ indicate higher carrier injection [15]. For our heterojunction, the value of $K$ is $1.02 \mathrm{~V}^{-1}$ obtained by fitting the $\mathrm{I}-\mathrm{V}$ curve in region-II. The small value of $K$ indicates that the thermal emission of carriers induced by surface states and traps is very low [17]. This implies that charge transport involves recombination tunnelling mechanism which is usually observed in wide band gap heterojunction.

Region-III is the high junction voltage region $(3.4 \mathrm{~V}<\mathrm{V}<10 \mathrm{~V})$. In this region, current-voltage characteristics was found to follow power law $\left(I \sim V^{L}\right)$, where $L$ is a constant, and for our diodes, the value of $L$ is $L \sim 1.5$. The value of $L$ less than 2 ascribes that the current is attributed to the trap charge limiting current (TCLC) which is associated with the distribution of trapped charges in a junction. This behaviour is usually observed in materials with low free charge carrier concentration [22-25].

The capacitance-voltage $(C-V)$ characteristics measured at the frequency of $1 \mathrm{MHz}$ at room temperature are shown in Figure 5. By plotting the inverse squared of area per junction capacitance $\left(A^{2} / C^{2}\right)$ against the applied reverse voltage $(V)$, the built-in potential $\left(V_{\mathrm{bi}}\right)$, barrier height $\left(\varphi_{B}\right)$, and doping concentration $\left(N_{\mathrm{d}}\right)$ can be extracted. The built-in potential is obtained by linear extrapolation of $A^{2} / C^{2}$ to the voltage axis (Figure 5). The intercept with the applied voltage axis yields a built-in potential of $0.8 \mathrm{~V}$. The doping concentration of $1.3 \times 10^{13} \mathrm{~cm}^{3}$ has been extracted from the slope of the linear segment of the curve by using equation (3)

$$
N_{d}=\frac{2}{q \varepsilon_{S} \varepsilon_{o}} \times \frac{\mathrm{d} V}{\mathrm{~d}\left(A^{2} / C^{2}\right)},
$$

where $\varepsilon_{\mathrm{S}}$ is the relative permittivity of $\mathrm{ZnO}$ having a value of 8.2. The barrier height of $1.12 \mathrm{~V}$ is obtained by using the following equation:

$$
\varphi_{B(C-V)}=V_{b i}+\frac{k T}{q} \ln \left(\frac{N_{C}}{N_{d}}\right),
$$

where $\mathrm{N}_{\mathrm{C}}$ is the effective density of states in the conduction band $(\mathrm{CB})$. Its value is $3.5 \times 10^{18} / \mathrm{cm}^{3}$ for $\mathrm{ZnO}$, obtained from the following equation:

$$
N_{C}=2\left(\frac{2 \pi m_{n}^{*} k T}{h^{2}}\right)^{3 / 2},
$$

where $m_{n}^{*} I$ the effective mass of electrons given by $m_{n}^{*}=0.27 m_{o}$. The barrier height obtained from the $C-V$ measurement is comparatively larger than the barrier heights obtained from the $I-V$ measurements. It is due to barrier inhomogenities, image force, and surface defects [26]. Secondly, interface traps do not respond to applied AC signals sometimes and do not contribute to capacitance at higher frequencies [27, 28].

At high forward voltages, the $I-V$ characteristics of devices are deviated from linearity due to the presence of series resistance and interface states. The current-voltage $(I-V)$ characteristics based on thermionic emission (TE) are given by the following equation:

$$
I=I_{o}\left[\exp \left(\frac{q\left(V-I R_{S}\right)}{n k T}\right)-1\right],
$$




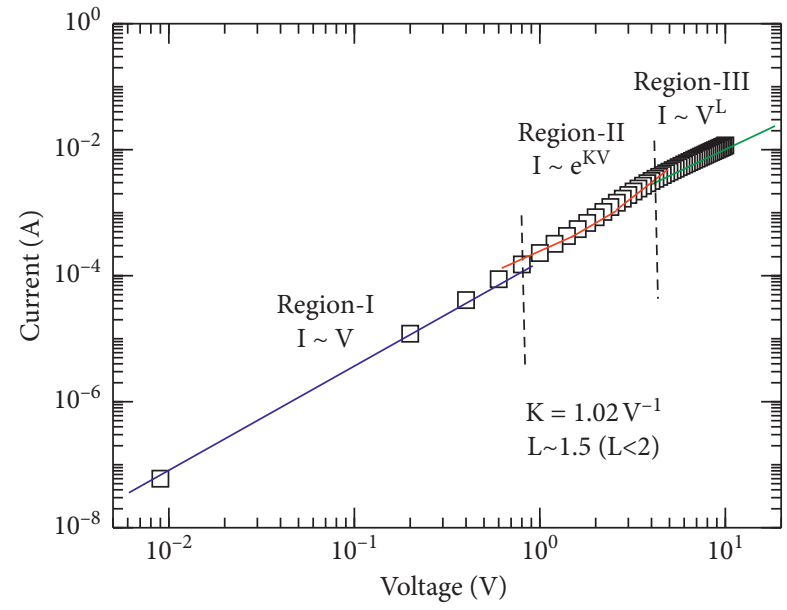

Figure 4: $\log -I$ vs. $\log -V$ characteristics of heterojunction.

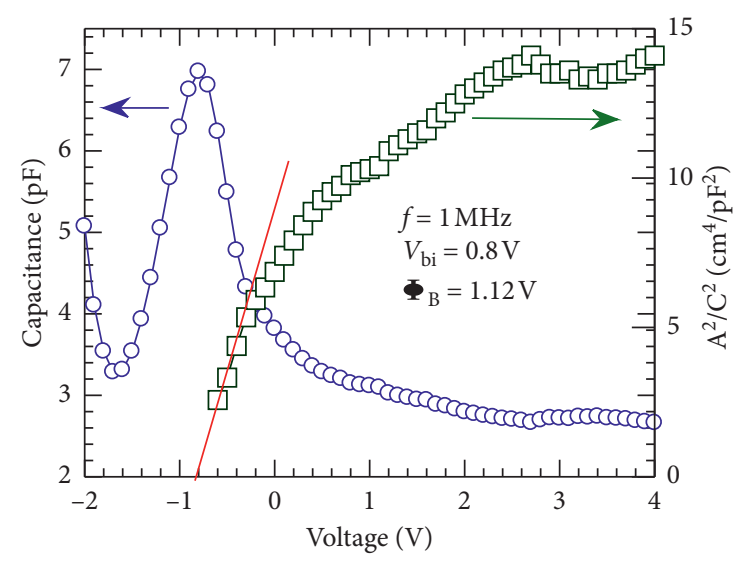

Figure 5: $C-V$ and $A / C^{2}$ vs. $V$ plot at the frequency of $1 \mathrm{MHz}$.

where $R_{S}$ is the series resistance which plays a crucial role and affects the device behaviour. We extracted series resistance by the method proposed by chueng [24, 29] given by the following equation:

$$
\frac{d V}{d(\ln I)}=R_{S} I+\frac{n k T}{q} .
$$

The plot of $d V / d(\ln I)$ vs. current is shown in Figure 6. On linearly fitting the curve, we obtained series resistance from the slope of the curve and ideality factor from its $y$ intercept. The obtained values of series resistance and ideality factor are $0.75 \mathrm{~K} \Omega$ and 5.7, respectively.

Furthermore, the barrier height and series resistance are also extracted by plotting function $H(I)$ vs. current given by the following equations:

$$
\begin{aligned}
& H(I)=V-\left(\frac{n k T}{q}\right) \ln \left(\frac{I}{A A^{*} T^{2}}\right) . \\
& H(I)=I R_{S}+n \varphi_{B} .
\end{aligned}
$$

The plot of $H(I)$ vs. current is shown in Figure 7. It is observed that $H(I)$ increases linearly with increasing current. The value of series resistance obtained from the slope of the curve is $0.73 \mathrm{~K} \Omega$, and barrier height is calculated from $y$ intercept using the ideality factor obtained by equation (6) and is found to be 0.70 . The values of series resistance calculated from the plot of $\mathrm{H}$ (I) vs. current is close to the value obtained from the plot of $\mathrm{dV} / \mathrm{d}(\ln \mathrm{I})$ versus current, implying the consistency of cheung's method. Series resistance extracted by the direct method $(\Delta \mathrm{V} / \Delta \mathrm{I})$ from currentvoltage characteristics is $0.77 \mathrm{~K} \Omega$.

The electrical parameters extracted for $\mathrm{p}-\mathrm{Si} / \mathrm{n}-\mathrm{ZnO}$ heterojunction have been compared with the literature as shown in Table 1. The values of series resistances are $0.77 \mathrm{~K} \Omega, 0.73 \mathrm{~K} \Omega$, and $0.75 \mathrm{~K} \Omega$ obtained by different methods for our heterojunction. These values are on higher side however less than the values of $3.2 \mathrm{~K} \Omega$ and 2.69/2.70 K $\Omega$ reported by $[30,33]$, respectively. Barrier height and ideality factor are in agreement with reported values. High values of ideality factor obtained for $\mathrm{Si} / \mathrm{ZnO}$ heterojunction diode are attributed to barrier inhomogeneity, series resistance, and presence of defects at the junction. The doping concentration for our junction is lower than the reported values in the literature. For $\mathrm{ZnO}$, this unintentional n-type doping is attributed to oxygen vacancies which act as donor-like native point defects. A small value of $\mathrm{Nd}$ may be due to less number of oxygen vacancies. High series resistance and small doping concentration are the limiting factors for majority carrier's injection under forward bias and reducing the rectification factor.

The smaller values of rectification factor and turn-on voltage are sometimes attributed to the small value of conduction band (CB) offset of $\mathrm{Si}$ and $\mathrm{ZnO}[28,34,35]$. Therefore, energy band (EB) diagrams have been studied. The energy band diagrams of for $\mathrm{Si} / \mathrm{ZnO}$ heterojunction are made according to the Anderson rule. EB structure for isolated regions before making the contact is shown in Figure 8(a) which depicts that $\mathrm{p}$-Si and n- $\mathrm{ZnO}$ form type-II staggered gap heterojunction. Both conduction and valence bands have band offset originated due to difference in electron affinities and band gaps.

The EB diagram at equilibrium is shown in Figure $8(\mathrm{~b})$. The CB offset $\left(\Delta \mathrm{E}_{\mathrm{C}}\right)$ of $0.15 \mathrm{eV}$ is obtained by applying the Anderson rule given by $\Delta \mathrm{E}_{\mathrm{C}}=\mathrm{q} \chi_{\mathrm{ZnO}^{-}} \mathrm{q} \chi_{\mathrm{Si}}$, where the electron affinities of $\mathrm{ZnO}\left(\mathrm{q} \chi_{\mathrm{ZnO}}\right)$ and $\mathrm{Si}\left(\mathrm{q} \chi_{\mathrm{Si}}\right)$ are $4.2 \mathrm{eV}$ and $4.05 \mathrm{eV}$, respectively $[36,37]$. Due to the small value $(0.15 \mathrm{eV})$, there might be a flow of electrons from the conduction band of $\mathrm{Si}$ to the conduction band of $\mathrm{ZnO}$. But in the valence band, the larger value of valence band offset $\left(\Delta \mathrm{E}_{\mathrm{V}}\right)$ prevents the movement of holes from $\mathrm{ZnO}$ to $\mathrm{Si}$, where $\quad \Delta \mathrm{E}_{\mathrm{V}}=\left(\mathrm{q} \chi_{\mathrm{ZnO}}+\mathrm{Eg}_{\mathrm{ZnO}}\right)-\left(\mathrm{q} \chi_{\mathrm{Si}}+\mathrm{Eg}_{\mathrm{Si}}\right)=\Delta \mathrm{E}_{\mathrm{C}}+\Delta \mathrm{E}_{\mathrm{g}}=$ $2.4 \mathrm{eV}$. Here, the band gaps of $\mathrm{ZnO}\left(\mathrm{Eg}_{\mathrm{ZnO}}\right)$ and $\mathrm{Si}\left(\mathrm{Eg}_{\mathrm{Si}}\right)$ are $3.37 \mathrm{eV}$ and $1.12 \mathrm{eV}$, respectively [38]. The position of Fermi level for $\mathrm{ZnO}$ is obtained by using equation (10), where $\mathrm{N}_{\mathrm{d}}$ is the donor concentration obtained from $\mathrm{A}^{2} / \mathrm{C}^{2}$ vs. V plot:

$$
N_{d}=n_{o}=N_{C} e^{-\left(E_{C}-E_{F}\right) / K T}
$$

As the carrier concentration in $\mathrm{p}-\mathrm{Si}$ is higher than $\mathrm{ZnO}$, the depletion region will be primarily extended in $\mathrm{ZnO}$. Thus, the current transport in the heterojunction is considered predominantly by the flow of electrons from $\mathrm{n}-\mathrm{ZnO}$ 


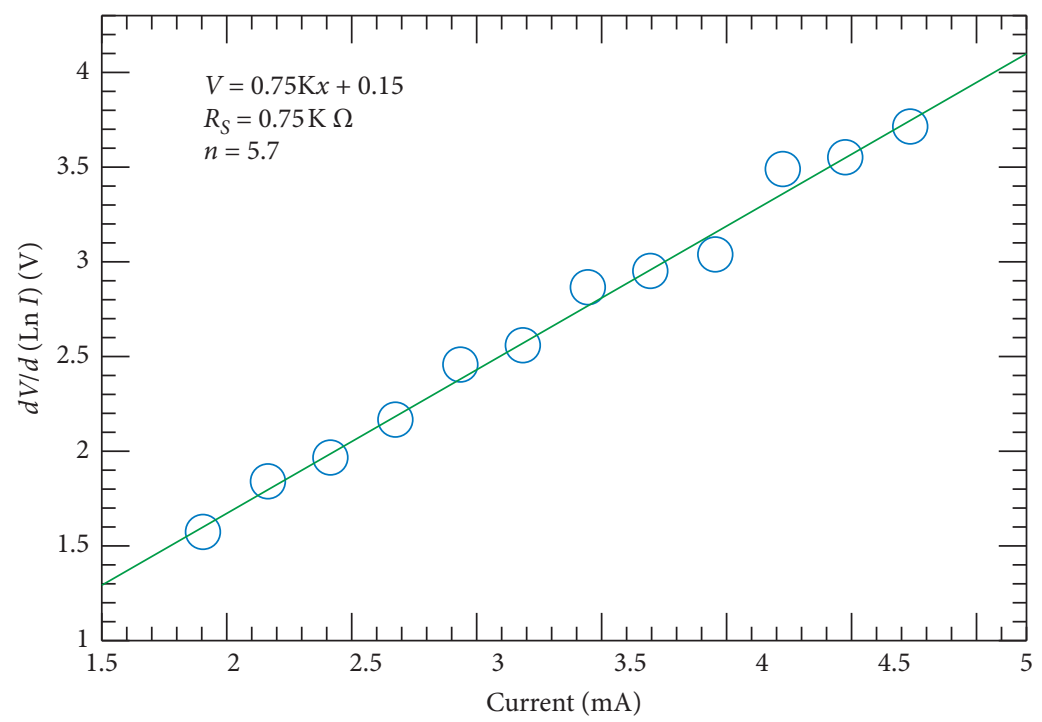

Figure 6: $d V / d(\ln I)$ vs. forward current.

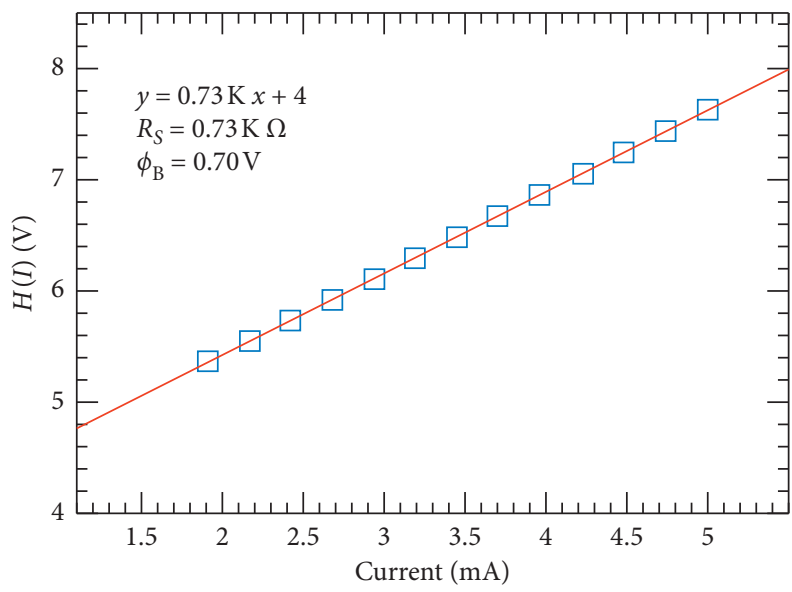

Figure 7: $H(I)$ vs. forward current.

TABLE 1: Extracted parameters of $\mathrm{Si} / \mathrm{ZnO}$ heterojunction and comparison with the previous work.

\begin{tabular}{|c|c|c|c|c|c|c|}
\hline & Rs $(\Omega)$ & $N$ & $F_{\text {в }}(\mathrm{eV})$ & Io (A) & $\mathrm{N}_{\mathrm{d}}\left(\mathrm{cm}^{-3}\right)$ & IF/IR \\
\hline Ref. [30] & - & 10 & 0.696 & $1 \times 10^{-6}$ & - & $22 @ \pm 3 \mathrm{~V}$ \\
\hline Ref. [31] & 92.5 & 2.16 & 0.59 & $3.66 \times 10^{-8}$ & - & $7350 @ \pm 2 V$ \\
\hline Ref. [26] & - & 7.19 & 0.7 & $9 \times 10^{-10}$ & - & - \\
\hline Ref. [32] & - & 3.2 & 0.74 & - & $4.02 \times 10^{15}$ & $840 @ \pm 5 V$ \\
\hline Ref. [33] & - & 2.38 & 0.74 & $1.1 \times 10^{-7}$ & $1.3 \times 10^{16}$ & $40 @ \pm 4 \mathrm{~V}$ \\
\hline \multirow[t]{4}{*}{ Our work } & $0.77 \mathrm{~K}$ & 2.7 & 0.7 & $6 \times 10^{-8}$ & $1.3 \times 10^{13}$ & $52 @ \pm 5 \mathrm{~V}$ \\
\hline & Chueng method & & & & & \\
\hline & $\operatorname{Rs}(\Omega)$ & $N$ & $\Phi_{\mathrm{B}}(\mathrm{eV})$ & & & \\
\hline & $d V / d \ln I$ & $H(I)$ & & & & \\
\hline Ref. [30] & $3.2 \mathrm{~K}$ & - & 7.02 & - & & \\
\hline Ref. [31] & 76 & 88 & 4.95 & 0.63 & & \\
\hline Ref. [33] & $2.69 \mathrm{~K}$ & $2.706 \mathrm{~K}$ & 3.69 & 0.85 & & \\
\hline Our work & $0.75 \mathrm{~K}$ & $0.73 \mathrm{~K}$ & 5.7 & 0.7 & & \\
\hline
\end{tabular}

to $\mathrm{p}$-Si [39]. Therefore, when the heterojunction is forward biased, there will be flow of electrons from $\mathrm{ZnO}$ into $\mathrm{Si}$ due to the lowering of junction barrier as shown in energy band diagram in Figure 8(c). The current increases with the increase in forward bias due to injection and recombination of electrons in p-Si. However, diode current tends to become 


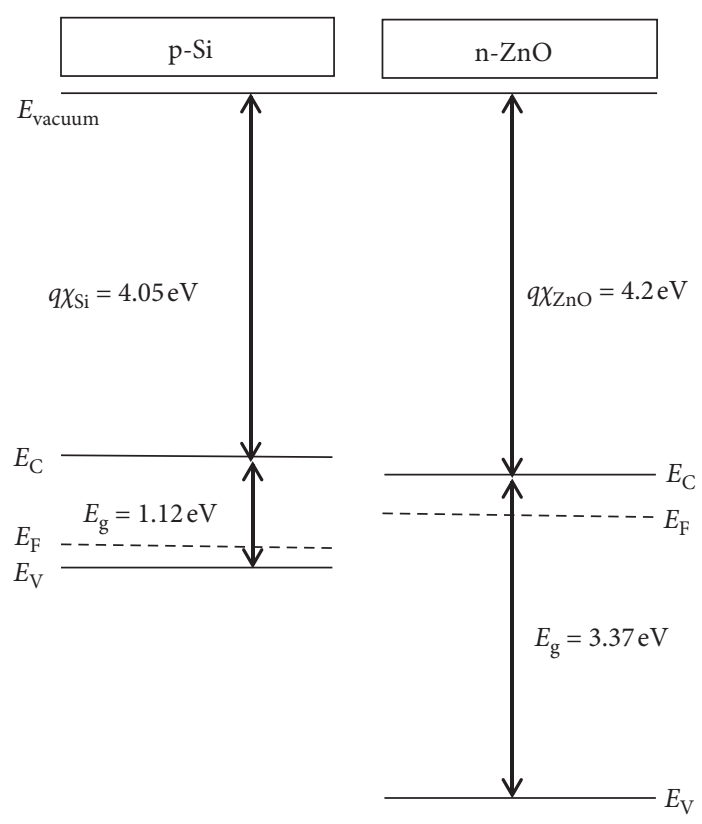

(a)

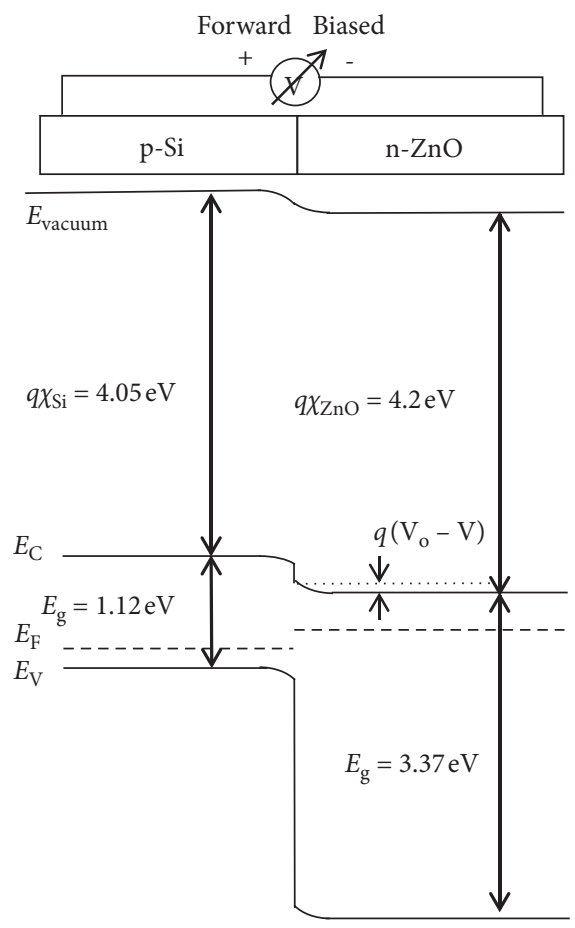

(c)

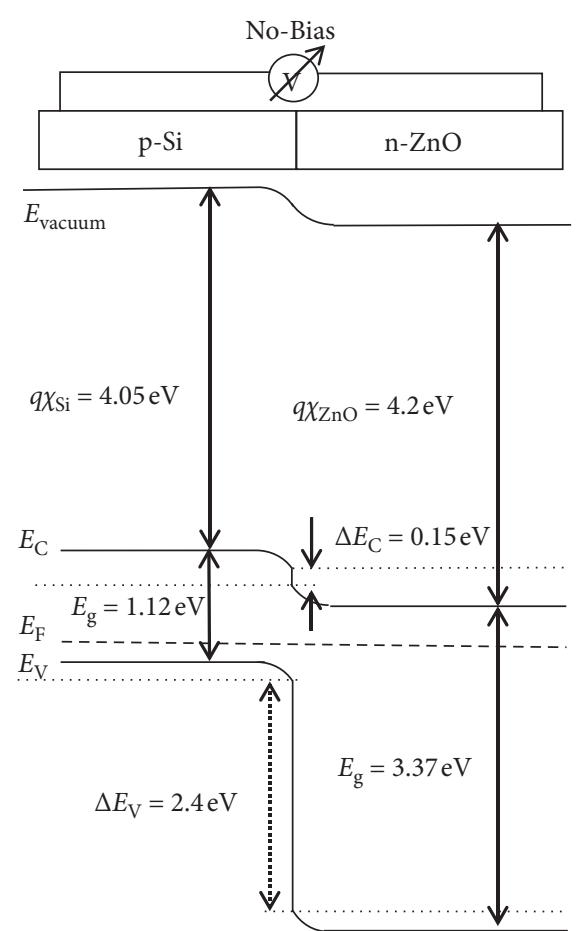

(b)

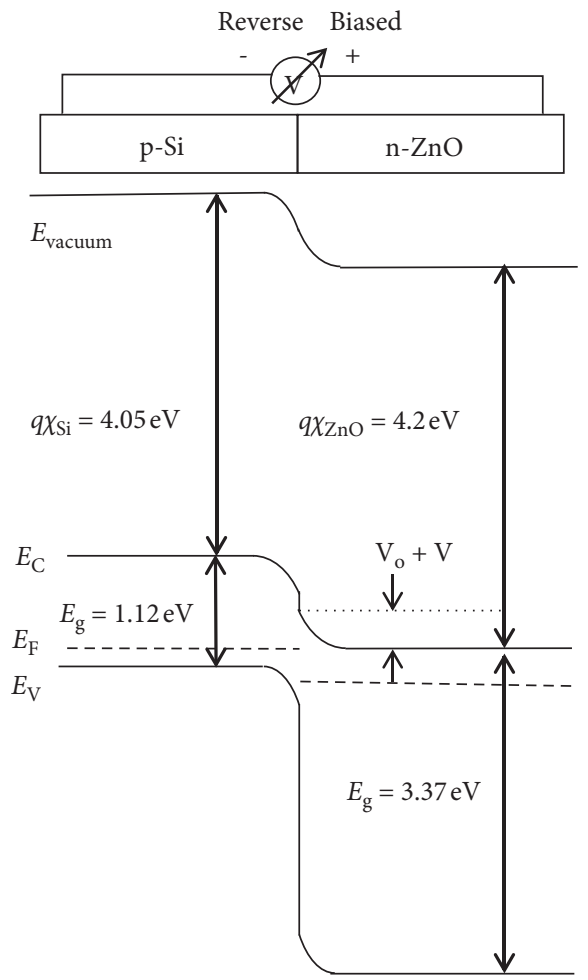

(d)

FiguRE 8: Energy band diagram: (a) isolated regions before forming the junction; (b) unbiased junction; (c) forward biased junction; (d) reverse biased junction.

constant at higher forward bias due to series resistance. A nominal increase in the reverse current will take place with increase in reverse voltage due to increase junction barrier as shown in Figure $8(d)$ of reverse bias.
The quality of the interface and density of interface states play a critical role in semiconductor devices. Several device parameters such as barrier height, ideality factor, and rectification factor get affected due to the presence of interface 
states [40]. The recombination in these thin insulating interfacial layers is sometimes the main loss mechanism in heterojunction especially in heterojunction solar cells.

The origin of these interface states are exactly not known; however, they are introduced intentionally at the interface due to extended air exposure, chemical reaction during fabrication processes, and incomplete covalent bonds at the interface [41, 42]. Such defects produce a large density of interface states distributed in the energy and also cause leakage currents.

The density of interface states $\left(N_{\mathrm{SS}}\right)$ can be extracted using $I-V$ and $C-V$ measured values using the following equation [43]:

$$
N_{S S}=\frac{1}{q}\left[\frac{\varepsilon_{i}}{\delta}\{n(V)-1\}-\frac{\varepsilon_{S}}{W_{D}}\right],
$$

where $\varepsilon_{\mathrm{i}}$ and $\varepsilon_{\mathrm{S}}$ are the permittivity of insulator (oxide) and semiconductor having values of 3.9 and 8.2 for $\mathrm{SiO}_{2}$ and $\mathrm{ZnO}$, respectively. Here, the values of $\varepsilon i / \delta$ and $n(\mathrm{~V})$ are extracted using the following equations:

$$
\begin{aligned}
& \frac{C_{i}}{A}=\frac{\varepsilon_{i}}{\delta}, \\
& n(V)=\frac{q V}{k T \ln \left(I / I_{o}\right)},
\end{aligned}
$$

where $n(v)$ is the voltage-dependent ideality factor, $\delta$ is the thickness of oxide layer, and $C_{i}$ is its capacitance, obtained from the following equation:

$$
C_{i}=C_{m a}\left[1+\left(\frac{G_{m a}}{\omega C_{m a}}\right)^{2}\right]
$$

The energy distribution of interface states below the conduction band is obtained by using the following equation:

$$
\begin{aligned}
E_{c}-E_{S S} & =q\left(\varphi_{e}-V\right) \\
\varphi_{e} & =\phi_{b o}+\left(1-\frac{1}{n(V)}\right)\left(V-I R_{S}\right)
\end{aligned}
$$

where $\varphi_{e}$ is the effective barrier height which can be obtained from equation (16).

The distribution of interface states below conduction band is shown in Figure 9. The interface state density is found high near the conduction band edge $\left(E_{\mathrm{C}}\right)$ and decreased monotonically with energy approaching the centre of the energy gap. The interface states density decreased from $8.38 \times 10^{12}$ to $5.83 \times 10^{11} \mathrm{eV}^{-1} \mathrm{~cm}^{-2}$ and from $\mathrm{Ec}-0.01$ to $E_{\mathrm{C}}-0.55 \mathrm{eV}$ below $E_{\mathrm{C}}$.

The distribution of densities of interface states (Nss) below the conduction band $(E c)$ is compared with the literature as shown in Table 2. The extracted density for our heterojunction is having a moderate range of values as compared with the reported values. As the interface states play an imperative role in electronic devices, they must be low in order to reduce the recombination and improve the junction performance.

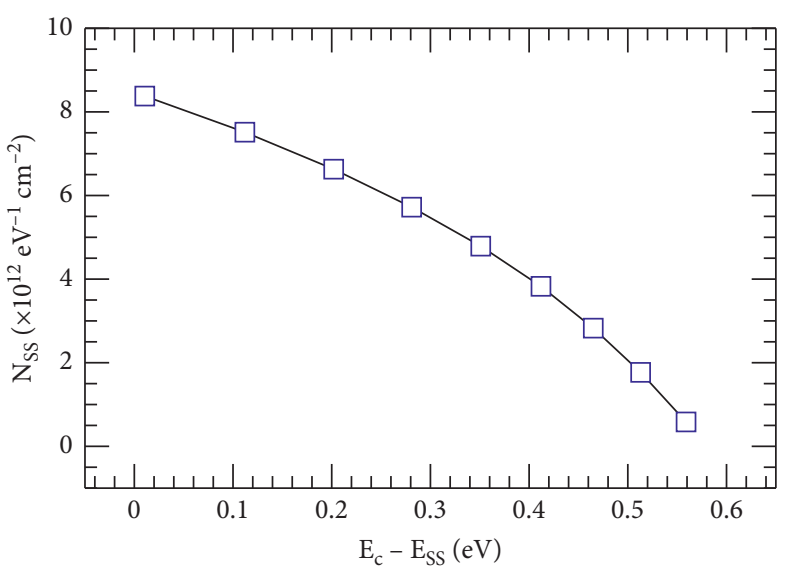

FIgURE 9: Distribution of interface states $\left(N_{\mathrm{SS}}\right)$ obtained from I-V and $\mathrm{C}-\mathrm{V}$ measurements.

TABle 2: Extracted interface state densities and the previous work.

\begin{tabular}{lcc}
\hline & $E c-E s(\mathrm{eV})$ & $N s s\left(\mathrm{eV}^{-1} \mathrm{~cm}^{-2}\right)$ \\
\hline Previous work [17] & $0.08-0.59$ & $5.20 \times 10^{11}-7.98 \times 10^{10}$ \\
Previous work [26] & $0.12-1.0$ & $1.90 \times 10^{8}-1.15 \times 10^{8}$ \\
Previous work [28] & $0.10-0.63$ & $3.18 \times 10^{13}-4.59 \times 10^{11}$ \\
Previous work [44] & $0.018-0.60$ & $3.00 \times 10^{12}-1.12 \times 10^{12}$ \\
Our work & $0.01-0.55$ & $8.38 \times 10^{12}-5.83 \times 10^{11}$ \\
\hline
\end{tabular}

\section{Conclusion}

Electrical characterization of $\mathrm{p}-\mathrm{Si} / \mathrm{n}-\mathrm{ZnO}$ nanorod heterojunction diode has been performed. The values of barrier height, ideality factor, rectification factor, and built-in potential have been extracted. For heterojunction, low values of rectification factor are attributed to small $\mathrm{CB}$ offset; therefore, the energy band diagram of the heterojunction has been studied and a small value of $(0.15 \mathrm{eV}) \mathrm{CB}$ offset was observed. Series resistance and interface states are attributed to the high values of ideality factor; therefore, series resistance and densities of interface states have been extracted. The values of series resistance were found to be $0.75,0.73$, and $0.77 \mathrm{~K} \Omega$ extracted by different methods. By I-V and C-V, the density of interface states from $8.38 \times 10^{12}-5.83 \times$ $10^{11} \mathrm{eV}^{-1} \mathrm{~cm}^{-2}$ and from $E \mathrm{c}-0.01$ to $E_{\mathrm{C}}-0.55 \mathrm{eV}$ below $E_{\mathrm{C}}$ was obtained. The value of interface states must be kept low in order to lessen the surface recombination and tunnelling.

\section{Data Availability}

The data used to support the findings of this study are available from the corresponding author upon request.

\section{Conflicts of Interest}

The authors declare that there are no conflicts of interest.

\section{Acknowledgments}

The authors appreciate the support and facilities by the Sultan Qaboos Oman IT chair office and Electronic Design 
Center at the NED University of Engineering and Technology.

\section{References}

[1] H. V. Wenckstern, M. Brandt, H. Schmidt et al., "Donor-like defects in $\mathrm{ZnO}$ substrate materials and $\mathrm{ZnO}$ thin films," Applied Physics A, vol. 88, no. 1, pp. 135-139, 2007.

[2] N. H. Alvi, M. Riaz, G. Tzamalis, O. Nur, and M. Willander, "Junction temperature in $\mathrm{n}-\mathrm{ZnO}$ nanorods/(p-4H-SiC, p-GaN, and p-Si) heterojunction light emitting diodes," SolidState Electronics, vol. 54, no. 5, pp. 536-540, 2010.

[3] B. Djurišić, X. Chen, Y. H. Leung, and A. M. C. Ng, "ZnO nanostructures: growth, properties and applications," Journal of Materials Chemistry, vol. 22, no. 14, p. 6526, 2012.

[4] V. Gaddam, R. R. Kumar, M. Parmar, M. M. Nayak, and K. Rajanna, "Synthesis of $\mathrm{ZnO}$ nanorods on a flexible phynox alloy substrate: influence of growth temperature on their properties," RSC Advances, vol. 5, no. 109, pp. 89985-89992, 2015.

[5] S. Fabbiyola and L. J. Kennedy, "Bandgap engineering in doped $\mathrm{ZnO}$ nanostructures for dye sensitized solar cell applications," Journal of Nanoscience and Nanotechnology, vol. 19, no. 5, pp. 2963-2970, 2019.

[6] F. Rahman, "Zinc oxide light-emitting diodes: a review," Optical Engineering, vol. 58, no. 1, p. 1, 2019.

[7] A. Janotti and C. G. Van De Walle, "Fundamentals of zinc oxide as a semiconductor," Reports on Progress in Physics, vol. 72, no. 12, p. 126501, 2009.

[8] P. H. L. Phan, Q. T. Tran, D. A. Dinh, K. K. Bok, C.-H. Hong, and T. V. Cuong, "The facile synthesis of novel $\mathrm{ZnO}$ nanostructure for galactose biosensor application," Journal of Nanomaterials, vol. 2019, Article ID 2364327, 8 pages, 2019.

[9] D. Adolph and T. Ive, "Nucleation and epitaxial growth of $\mathrm{ZnO}$ on GaN (0001)," Applied Surface Science, vol. 307, pp. 438-443, 2014.

[10] C. Yuen, S. F. Yu, S. P. Lau, Rusli, and T. P. Chen, "Fabrication of $\mathrm{n}-\mathrm{ZnO}: \mathrm{A} V \mathrm{p}-\mathrm{SiC}(4 \mathrm{H})$ heterojunction light-emitting diodes by filtered cathodic vacuum arc technique," Applied Physics Letters, vol. 86, no. 24, p. 241111, 2005.

[11] C.-H. Tang, K.-Y. Chen, and C.-Y. Chen, "Solution-processed $\mathrm{ZnO} / \mathrm{Si}$ based heterostructures with enhanced photocatalytic performance," New Journal of Chemistry, vol. 42, no. 16, pp. 13797-13802, 2018.

[12] D. G. Georgiadou, M. Ulmeanu, M. Kompitsas, P. Argitis, and M. Kandyla, "Scalable fabrication of nanostructured $\mathrm{p}-\mathrm{Si} / \mathrm{n}$ $\mathrm{ZnO}$ heterojunctions by femtosecond-laser processing," Materials Research Express, vol. 1, no. 4, Article ID 045902, 2014.

[13] K. L. P. Thi, L. T. Nguyen, A. T. Dao, N. H. Ke, and V. T. H. Le, "Fabrication and characterization of $\mathrm{n}-\mathrm{ZnO}$ nanorods/p-Si (100) heterojunction," Journal of Nonlinear Optical Physics \& Materials, vol. 24, no. 04, Article ID 1550050, 2015.

[14] A.-H. Umar, R. I. Badran, A. Al-Hajry, and S. Al-Heniti, "Fabrication and characterization of $\mathrm{n}-\mathrm{ZnO}$ hexagonal nanorods/p-Si heterojunction diodes: temperature-dependant electrical characteristics," Journal of Nanoscience and Nanotechnology, vol. 15, no. 7, pp. 4969-4975, 2015.

[15] H.-L. Lu, Y.-Z. Gu, Y. Zhang et al., "Improved photoelectrical properties of $\mathrm{n}-\mathrm{ZnO} / \mathrm{p}-\mathrm{Si}$ heterojunction by inserting an optimized thin Al_2O_3 buffer layer," Optics Express, vol. 22, no. 18, p. 22184, 2014

[16] M. Law, L. E. Greene, J. C. Johnson, R. Saykally, and P. Yang, "Nanowire dye-sensitized solar cells," Nature Materials, vol. 4 , no. 6, pp. 455-459, 2005.
[17] S. M. Faraz, O. Nur, M. Willander, and Q. Wahab, "Interface states density of $\mathrm{Au} / \mathrm{n}-\mathrm{ZnO}$ nanorods Schottky diodes," IOP Conference Series: Materials Science and Engineering, vol. 34, Article ID 012006, 2012.

[18] H. Alnoor, C. O. Chey, G. Pozina et al., "Effect of precursor solutions stirring on deep level defects concentration and spatial distribution in low temperature aqueous chemical synthesis of zinc oxide nanorods," AIP Advances, vol. 5, no. 8, Article ID 087180, 2015.

[19] H. Alnoor, G. Pozina, V. Khranovskyy et al., "Influence of $\mathrm{ZnO}$ seed layer precursor molar ratio on the density of interface defects in low temperature aqueous chemically synthesized $\mathrm{ZnO}$ nanorods/GaN light-emitting diodes," Journal of Applied Physics, vol. 119, no. 16, p. 165702, 2016.

[20] H.-S. Choi, M. Vaseem, S. G. Kim, Y.-H. Im, and Y.-B. Hahn, "Growth of high aspect ratio $\mathrm{ZnO}$ nanorods by solution process: effect of polyethyleneimine," Journal of Solid State Chemistry, vol. 189, pp. 25-31, 2012.

[21] N. S. Ridhuan, K. A. Razak, Z. Lockman, and A. A. Aziz, "Structural and morphology of $\mathrm{ZnO}$ nanorods synthesized using $\mathrm{ZnO}$ seeded growth hydrothermal method and its properties as UV sensing," PLoS One, vol. 7, no. 11, 2012.

[22] D. Sang, Q. Wang, Q. Wang et al., "Improved electrical transport properties of an $\mathrm{n}-\mathrm{ZnO}$ nanowire/p-diamond heterojunction," RSC Advances, vol. 8, no. 50, pp. 2880428809, 2018.

[23] F. Gao, D. Zhang, J. Wang et al., "Ultraviolet electroluminescence from $\mathrm{Au}-\mathrm{ZnO}$ nanowire Schottky type light-emitting diodes," Applied Physics Letters, vol. 108, no. 26, p. $261103,2016$.

[24] S. Ilican, K. Gorgun, S. Aksoy, Y. Caglar, and M. Caglar, "Fabrication of $\mathrm{p}$-Si/n-ZnO:Al heterojunction diode and determination of electrical parameters," Journal of Molecular Structure, vol. 1156, pp. 675-683, 2018.

[25] M. A. Rafiq, "Carrier transport mechanisms in semiconductor nanostructures and devices," Journal of Semiconductors, vol. 39, no. 6, Article ID 061002, 2018.

[26] M. Y. S. Hussain, N. Bano, O. Nur, and M. Willander, "Interface trap characterization and electrical properties of Au$\mathrm{ZnO}$ nanorod Schottky diodes by conductance and capacitance methods," Journal of Applied Physics, vol. 112, no. 6, Article ID 064506, 2012.

[27] D. K. Schroder, Semiconductor Material and Device Characterization, Wiley-Interscience, Hoboken, NJ, USA, 3rd edition, 2007.

[28] D. Somvanshi and S. Jit, "Analysis of temperature-dependent electrical characteristics of $\mathrm{n}-\mathrm{ZnO}$ nanowires (NWs)/p-Si heterojunction diodes," IEEE Transactions on Nanotechnology, vol. 13, no. 1, pp. 62-69, 2014.

[29] S. K. Cheung and N. W. Cheung, "Extraction of Schottky diode parameters from forward current-voltage characteristics," Applied Physics Letters, vol. 49, no. 2, pp. 85-87, Jul.1986.

[30] R. Labar and T. K. Kundu, "Barrier inhomogeneities in $\mathrm{n}-\mathrm{ZnO} / \mathrm{p}$-Si heterojunctions fabricated with $\mathrm{ZnO}$ nanorods," Journal of Electronic Materials, vol. 47, no. 7, pp. 3628-3633, 2018.

[31] S. K. Akay, S. Sarsıc1, and H. K. Kaplan, "Determination of electrical parameters of $\mathrm{ZnO} / \mathrm{Si}$ heterojunction device fabricated by RF magnetron sputtering," Optical and Quantum Electronics, vol. 50, no. 10, 2018.

[32] S. Sharma, B. C. Bayer, V. Skakalova, G. Singh, and C. Periasamy, "Structural, electrical, and UV detection properties of $\mathrm{ZnO} / \mathrm{Si}$ heterojunction diodes," IEEE Transactions on Electron Devices, vol. 63, no. 5, pp. 1949-1956, 2016. 
[33] R. N. Gayen and S. R. Bhattacharyya, "Electrical characteristics and rectification performance of wet chemically synthesized vertically aligned $\mathrm{n}-\mathrm{ZnO}$ nanowire/p-Si heterojunction," Journal of Physics D: Applied Physics, vol. 49, no. 11, p. 115102, 2016.

[34] X. Fang, X. Wang, D. Zhao et al., "Electroluminescence of $\mathrm{ZnO}$ nanorods/ZnMgO films/p-SiC structure heterojunction LED," Physica E: Low-Dimensional Systems and Nanostructures, vol. 59, pp. 93-97, 2014.

[35] V. Kabra, L. Aamir, and M. M. Malik, "Low cost, p-ZnO/n-Si, rectifying, nano heterojunction diode: fabrication and electrical characterization," Beilstein Journal of Nanotechnology, vol. 5, pp. 2216-2221, 2014.

[36] L. J. Brillson and Y. Lu, "ZnO Schottky barriers and Ohmic contacts," Journal of Applied Physics, vol. 109, no. 12, p. 121301, 2011.

[37] K. Bandopadhyay and J. Mitra, "Spatially resolved photoresponse on individual $\mathrm{ZnO}$ nanorods: correlating morphology, defects and conductivity," Scientific Reports, vol. 6, no. $1,2016$.

[38] A. B. F. Martinson, J. W. Elam, J. T. Hupp, and M. J. Pellin, "ZnO nanotube based dye-sensitized solar cells," Nano Letters, vol. 7, no. 8, pp. 2183-2187, 2007.

[39] X. D. Chen, C. C. Linga, S. Fung, and C. D. Beling, "Current transport studies of $\mathrm{ZnO} / \mathrm{p}-\mathrm{Si}$ heterostructures grown by plasma immersion ion implantation and deposition," Applied Physics Letters, vol. 88, no. 13, p. 2104, 2006.

[40] Y. F. Chan, W. Su, C. X. Zhang et al., "Electroluminescence from ZnO-nanofilm/Si-micropillar heterostructure arrays," Optics Express, vol. 20, no. 22, p. 24280, 2012.

[41] B. G. Streetman and S. K. Banerjee, Solid State Electronic Devices, Prentice-Hall, Englewood Cliffs, NJ, USA, 6th edition, 2006.

[42] L. J. Brillson, "Advances in understanding metal-semiconductor interfaces by surface science techniques," Journal of Physics and Chemistry of Solids, vol. 44, no. 8, pp. 703-733, 1983.

[43] H. C. Card and E. H. Rhoderick, "Studies of tunnel MOS diodes I. Interface effects in silicon Schottky diodes," Journal of Physics D: Applied Physics, vol. 4, no. 10, pp. 1589-1601, 1971.

[44] R. N. Gayen, S. R. Bhattacharyya, and P. Jana, “Temperature dependent current transport of $\mathrm{Pd} / \mathrm{ZnO}$ nanowire Schottky diodes," Semiconductor Science and Technology, vol. 29, no. 9, Article ID 095022, 2014. 